\title{
A simple real-time polymerase chain reaction (PCR)-based assay for authentication of the Chinese Panax ginseng cultivar Damaya from a local ginseng population
}

\author{
H. Wang', J. Wang ${ }^{2}$ and G. Li $^{2}$ \\ ${ }^{1}$ School of Life Science, Yantai University, Yantai, China \\ ${ }^{2}$ School of Pharmacy, Yantai University, Yantai, China \\ Corresponding author: G. Li \\ E-mail: 1syq_003@163.com
}

Genet. Mol. Res. 15 (2): gmr.15028801

Received May 16, 2016

Accepted June 3, 2016

Published June 24, 2016

DOI http://dx.doi.org/10.4238/gmr.15028801

\begin{abstract}
Panax ginseng is one of the most important medicinal plants in the Orient. Owing to its increasing demand in the world market, cultivated ginseng has become the main source of medicinal material. Among the Chinese ginseng cultivars, Damaya commands higher prices and is grown in significant proportions among the local ginseng population. Due to the lack of rapid and accurate authentication methods, Damaya is distributed among different cultivars in the local ginseng population in China. Here, we identified a unique, Damayaspecific single nucleotide polymorphism (SNP) site present in the second intron of mitochondrial cytochrome c oxidase subunit 2 ( $\operatorname{cox} 2$ ). Based on this SNP, a Damaya cultivar-specific primer was designed and an allele-specific polymerase chain reaction (PCR) was optimized for the effective molecular authentication of Damaya. We designed a method by combining a simple DNA isolation method with real-time allele-specific PCR using SYBR Green I fluorescent dye, and proved its efficacy in clearly discriminated Damaya cultivar from other Chinese
\end{abstract}


ginseng cultivars according to the allelic discrimination analysis. Hence, this study provides a simple and rapid assay for the differentiation and conservation of Damaya from the local Chinese ginseng population.

Key words: Panax ginseng; Damaya cultivar; cox2; SNP; Allele-specific PCR; Real-time PCR

\section{INTRODUCTION}

Panax ginseng C.A. Meyer (Araliaceae), with thousands of years of history, has been traditionally recognized as a medicinal plant with mysterious powers in the Orient (Choi et al., 2013). Particularly in China and Korea, this plant is known as the "The King of Herbs". The key active constituent of $P$. ginseng is ginsenosides. Besides, it contains non-saponin components with effective pharmacological activities, such as polysaccharides, peptides, polyacetylene compounds, and fatty acids (Choi, 2008). Modern science has identified P. ginseng as a herbal remedy with several pharmacological attributes, namely, improved brain function (Zhang et al., 2008), enhanced immune system function, improved climacteric disorder, improved sexual function, adjusted blood pressure, pain-relieving effects, anti-fatigue activity, anticancer activity, anti-oxidative effects and anti-aging effects (Choi, 2008; Jee et al., 2014).

Owing to its increasing demand in the world market, cultivated ginseng rather than the wild has become the main source of medicinal material. Korea started cultivating ginseng in the 16th Century and as a result of years of selection and breeding processes, a series of cultivars with characteristics unique to Korean ginseng have been developed (Wang et al., 2009). Mainly cultivated cultivars of ginseng in China include, Damaya, Ermaya, Biaotiao, Changbo, and Huangguo. These cultivars are classified according to their phenotypic traits (Zhao et al., 2007) and strictly speaking, are landraces that resulted from natural selection and random genetic mutations. Because of the lack of rapid and accurate authentication methods, different cultivars of ginseng are distributed in the local population, causing serious effects on the stability of yield and quality. This is a major bottleneck for the standard cultivation and selection of superior ginseng cultivars. Damaya, a primary cultivar grown in significant proportion among local ginseng population, has profound medicinal and economic value, and commands higher prices. Therefore, an effective authentication method for the selection and conservation of Damaya from local Chinese ginseng population is essential.

In contrast to phenotypic characteristics, DNA markers provide an efficient tool for germplasm characterization, conservation, and management. Pioneering studies have developed different types of molecular markers for Korean ginseng cultivars (Sun et al., 2010, 2011; Wang et al., 2009, 2010, 2011), but very few molecular marker are reported for the specific authentication of Chinese ginseng cultivars. In this study, we exploited a single nucleotide polymorphism (SNP) marker present in the mitochondrial cox2 intron II region of Chinese ginseng cultivar Damaya, and constructed a real-time polymerase chain reaction (PCR)-based assay for its authentication from local ginseng population.

\section{MATERIAL AND METHODS}

\section{Plant material}

Ginseng breeders authenticated and collected leaf samples of five ginseng cultivars 
from ginseng fields, namely, Damaya, Ermaya, Biantiao, Changbo, and Huangguo from Jilin Province, China. Chinese $P$. notoginseng, also known as "Sanqi," was collected from Yunnan Province (Table 1). All the voucher specimens were identified by Prof. Guisheng Li and deposited at the College of Pharmacy, Yantai University.

Table 1. Ginseng plant materials used in this study.
\begin{tabular}{l|l|l|c}
\hline Ginseng samples & Voucher & Location & Accession Nos. of cox2 intron II \\
\hline Damaya & Da01 & Jilin, China & KT345971 \\
\hline Ermaya & Er01 & Jilin, China & KT345972 \\
\hline Biantiao & Bi01 1 & Jilin, China & KT345973 \\
\hline Changbo & Ch01 & Jilin, China & KT345974 \\
\hline Huangguo & Hu01 & Jilin, China & HM76875 \\
\hline$P$. notoginseng & GB096 & Yunnan, China \\
\hline
\end{tabular}

\section{DNA isolation}

Genomic DNA was isolated using two different methods: 1) Young leaves of five ginseng cultivars were ground in liquid nitrogen and genomic DNA was extracted from these leaves using EasyPure Plant Genomic DNA Kit (TransGen Biotech, Beijing). 2) 20-25 mg of tissue was punched from fresh leaves and the leaf punches were placed into $1.5-\mathrm{mL}$ tubes. The leaf tissues were then ground in $50 \mu \mathrm{L} 4 \mathrm{M} \mathrm{NaOH}$ using TissueLyser II (QIAGEN), until no pieces of tissue remained. Five microliters of the extracted solution was transferred to $295 \mu \mathrm{L}$ $100 \mathrm{mM}$ Tris buffer (Wang et al., 1993) and stored until further use for real-time PCR analysis.

\section{PCR amplification of mitochondrial cox2 intron II region}

The mitochondrial cox 2 intron II regions of five ginseng cultivars were amplified using the following primers: CoxI2F (5'-GAGTTATTCCAGCTTCTTCATG-3') and CoxI2R (5'-ATGCCTCTTGACTTTAGTATGG-3'). PCR was performed in a total volume of $20 \mu \mathrm{L}$ and the reaction mixture consisted of $0.5 \mu \mathrm{M}$ each of forward and reverse primer, $20 \mathrm{ng}$ template DNA, and $10 \mu \mathrm{L} 2 \mathrm{X}$ EasyTaq PCR SuperMix (TransGen Biotech). PCR cycling parameters were as follows: initial denaturation at $94^{\circ} \mathrm{C}$ for $4 \mathrm{~min}$, followed by 35 cycles including denaturing at $94^{\circ} \mathrm{C}$ for $30 \mathrm{~s}$, annealing at $60^{\circ} \mathrm{C}$ for $30 \mathrm{~s}$, and elongation at $72^{\circ} \mathrm{C}$ for $1 \mathrm{~min}$, with a final extension at $72^{\circ} \mathrm{C}$ for $5 \mathrm{~min}$. PCR products were separated on $1.0 \%$ agarose gel, stained with ethidium bromide, and visualized under UV.

\section{DNA sequencing and sequence analysis}

PCR amplicons corresponding to five ginseng cultivars were purified using an EasyPure PCR Purification kit (TransGen Biotech) and were sequenced in both directions using the BigDye Terminator v3.1 Cycle Sequencing Kit (Applied Biosystems) with an ABI PRISM 3730 sequencer. Sequence data were analyzed using DNAstar software. ClustalW program was used for multiple sequence alignments (Larkin et al., 2007).

\section{Allele-specific PCR}

Primer DaF (5'-ATTCAATGGAGGACTTCACA-3') was designed for the specific identification of Damaya cultivar according to the detected SNP site. The substitution of A to 
T within the third base from the 3 ' terminus was deliberately introduced to ensure the required allele specificity (Kwok et al., 1994). For the molecular authentication of Damaya, allelespecific PCR was performed using primers DaF, Cox2IF, and Cox2IR. Cox2IF and Cox2IR were included in the assay as a positive control for each sample. PCR reaction was performed in a total volume of $20 \mu \mathrm{L}$ and the reaction mixture consisted of $20 \mathrm{ng}$ template DNA, $10 \mu \mathrm{L}$ 2X EasyTaq PCR SuperMix (TransGen Biotech), $0.125 \mu \mathrm{M}$ Cox2IF, $0.5 \mu \mathrm{M}$ Cox2IR, and $0.5 \mu \mathrm{M}$ DaF. PCR cycling parameters were as follows: pre-denaturation at $94^{\circ} \mathrm{C}$ for $4 \mathrm{~min}$, followed by 33 cycles including denaturation at $94^{\circ} \mathrm{C}$ for $30 \mathrm{~s}$, annealing at $64^{\circ} \mathrm{C}$ for $30 \mathrm{~s}$, and extension at $72^{\circ} \mathrm{C}$ for $30 \mathrm{~s}$, with a final elongation at $72^{\circ} \mathrm{C}$ for $7 \mathrm{~min}$.

\section{Real-time PCR assay}

To facilitate rapid selection of Damaya from local ginseng population, a real-time PCR assay was performed on a Rotor-Gene ${ }^{\mathrm{TM}} 6000$ machine (Corbett Life Science, Australia) with DNA isolated using the second method mentioned above. The reaction was performed in a total volume of $10 \mu \mathrm{L}$. The reaction mixture consisted of 5-16 ng DNA, $5 \mu \mathrm{M}$ each primer (DaF and Cox2IR), and $5 \mu \mathrm{L} 2 \mathrm{X}$ SensiMixPlus SYBR Green I Mastermix (Quantace Ltd, Australia). PCR cycling parameters were as follows: pre-denaturation at $95^{\circ} \mathrm{C}$ for $10 \mathrm{~min}$, followed by 40 cycles including denaturation at $95^{\circ} \mathrm{C}$ for $10 \mathrm{~s}$, annealing at $64^{\circ} \mathrm{C}$ for $15 \mathrm{~s}$, and extension at $72^{\circ} \mathrm{C}$ for $20 \mathrm{~s}$. The melting analysis conditions consisted of a ramp from $85^{\circ} \mathrm{C}$ to $98^{\circ} \mathrm{C}$, rising by $1^{\circ} \mathrm{C}$ at each step. Allelic discrimination analysis method was used for the molecular authentication of Damaya.

\section{RESULTS}

\section{Multiple sequence alignment and SNP analysis}

The amplified PCR product of cox 2 intron II domain was found to be $771 \mathrm{bp}$. The sequences of cox 2 intron II region of all five cultivars were registered in GenBank with the following accession numbers: KT345971 (Damaya), KT345972 (Ermaya), KT345973 (Biantiao), KT345974 (Changbo), and KT345975 (Huangguo). Multiple sequence alignment results indicated that cox2 intron II domains of all five Chinese ginseng cultivars were almost identical. But, the analysis identified an exceptionally unique mutation site specific to Damaya. As shown in Figure 1, Damaya has A at the 386th nucleotide position, which was replaced with $\mathrm{C}$ in all other Chinese ginseng cultivars. Based on this Damaya-specific SNP site, primer $\mathrm{DaF}$ was designed for the specific authentication of Damaya cultivar.

\section{Allele-specific PCR authentication of Damaya cultivar}

Molecular identification of Damaya was carried out using allele-specific PCR with three primers, namely, Cox2IF, Cox2IR, and Damaya-specific primer DaF. As shown in Figure 2, with Cox2IF and Cox2IR primers, all ginseng samples yielded PCR amplicons of $771 \mathrm{bp}$, but with $\mathrm{DaF}$ and Cox2IR primers, Damaya cultivar alone generated a specific $410 \mathrm{bp}$ fragment. This experiment was repeated many times and no false positives were detected. PCR applicant length polymorphism profile of different cultivars proved that the unique mismatch introduced in Damaya cultivar-specific primer significantly reduced artificial products of the non-specific 
allele. After cloning, the Damaya cultivar specific 410-bp PCR fragment was recycled and sequenced. This sequence was identical with the sequence shown in Figure 1. Thus, our results confirm the ability of Damaya specific-primer based allele-specific PCR assay to be able to efficiently differentiate Damaya from other Chinese ginseng cultivars.

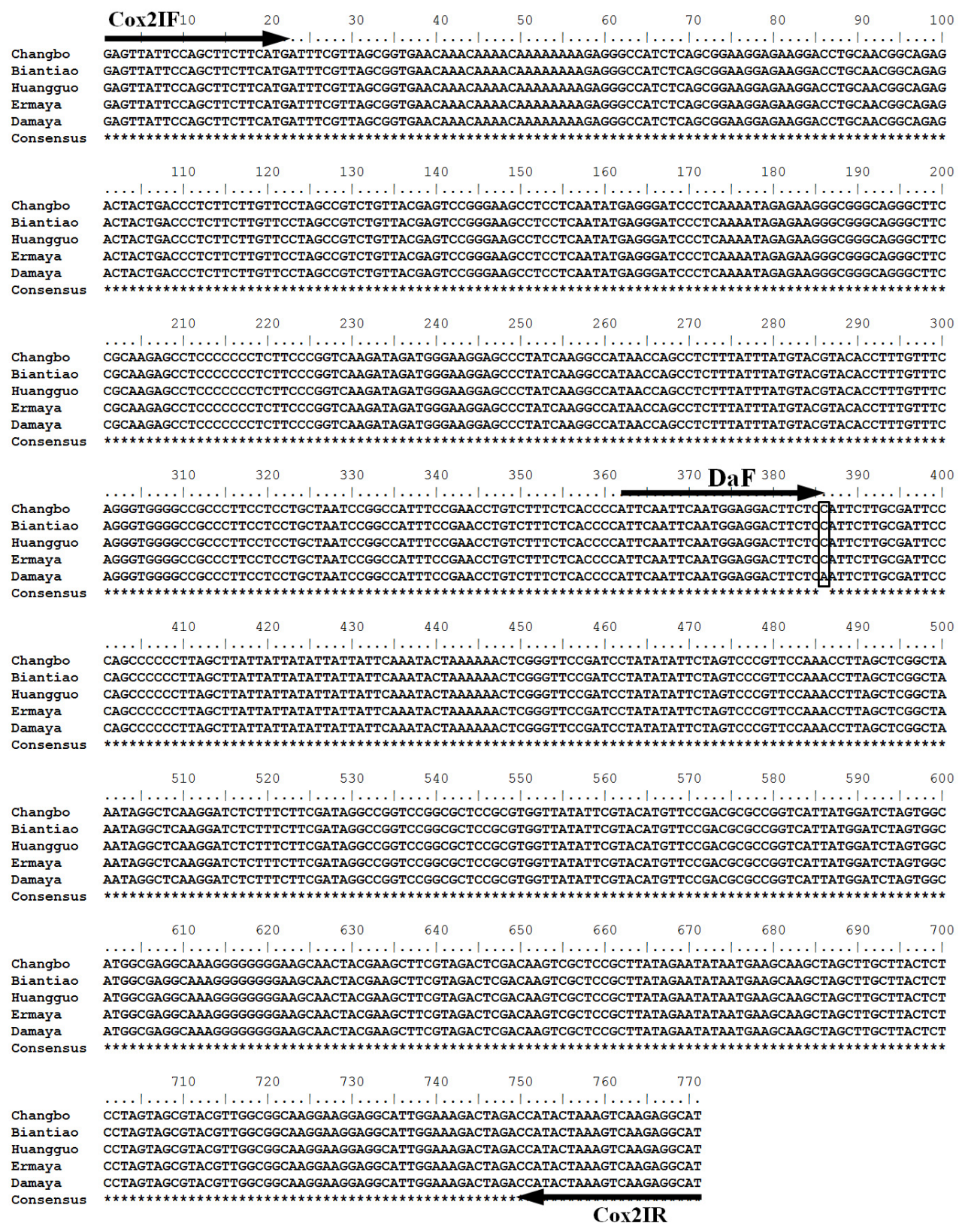

Figure 1. Result of multiple sequence alignment of Chinese ginseng cultivars. 


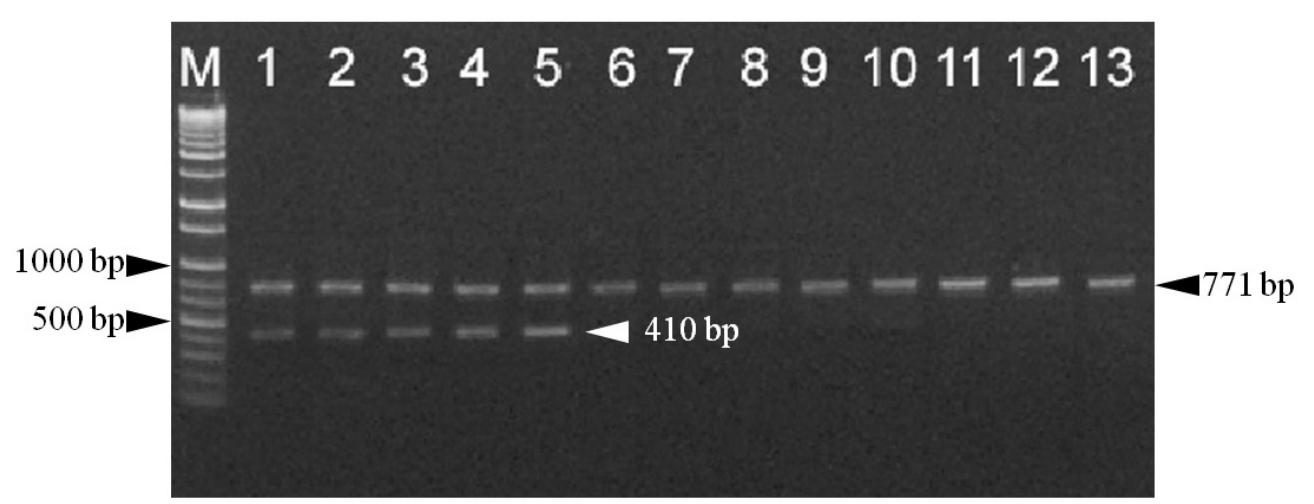

Figure 2. Agarose gel image representing the result of allele-specific PCR. Lane $M=1000$-bp DNA ladder; lanes $1-5=$ Damaya; lanes 6 and $7=$ Ermaya; lanes 8 and $9=$ Biantiao; lanes 10 and $11=$ Changbo; lanes 12 and $13=$ Huangguo.

\section{Real-time PCR assay for authentication of Damaya cultivar}

Although allele-specific PCR is a simple technique for the identification of Damaya, the tedious process of DNA isolation and agarose gel-based assays make it unsuitable for screening large number of samples. In order to address this problem, a technique was devised combining a simple DNA isolation method and real-time allele-specific PCR with SYBR Green I fluorescent dye (Wang et al., 1993). The principle of the assay was based on the increase in fluorescence intensity caused by the binding of SYBR Green I dye to double-stranded DNA. At the beginning of the PCR amplification process, the reaction mixture contains denatured DNA, primers, and the unbound SYBR Green I dye molecules, which show weak fluorescence producing a minimal background fluorescence signal that is subtracted during computer analysis. As more and more double-stranded DNA products are formed by PCR amplification, the fluorescence signal detected becomes proportionally more intense (D'Andrea et al., 2009). Therefore, the presence or absence of fluorescence signal detected in real-time PCR indicates whether the specific A allele is present in the target. Analyses of the amplification profile of five ginseng cultivars, as shown in Figure 3, showed that only Damaya cultivar generated fluorescence signal during real-time PCR amplification. When the threshold was set in allelic discrimination analysis, Damaya was regarded as the wild type while the other cultivars were not amplified by PCR. To validate the reproducibility of this authentication method, 70 Damaya samples collected from different locations were analyzed, and the method yielded 100\% accurate results (Figure 4). Hence, our study has optimized a simple and reliable method to differentiate Damaya cultivar from other Chinese ginseng cultivars accurately.

\section{DISCUSSION}

Germplasm resources are the major genetic source for the ginseng industry. The protection and selection of existing ginseng cultivars are important for its conservation and for the breeding of new cultivars. However, owing to their morphological similarity, closely 


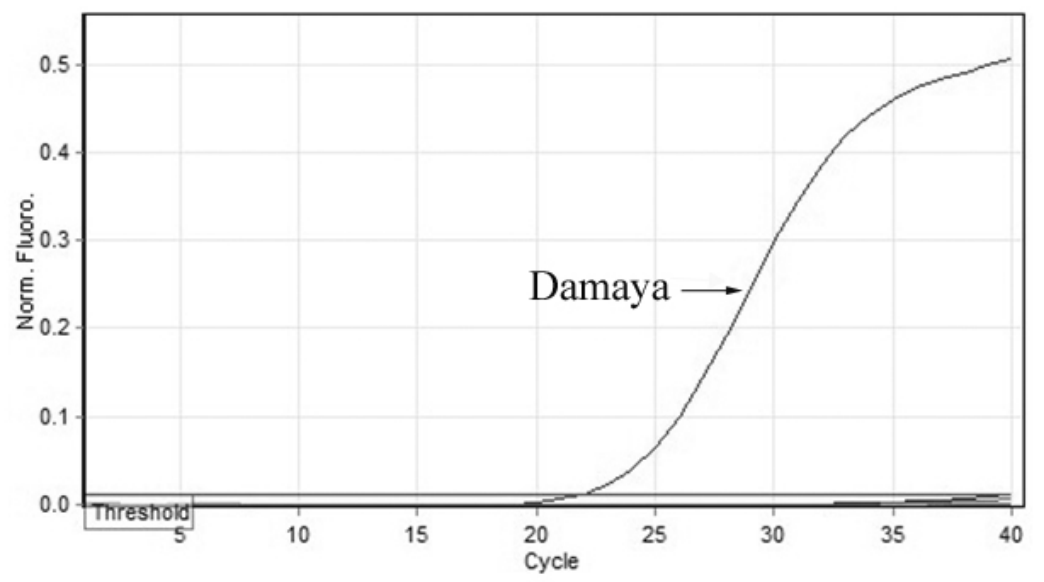

\begin{tabular}{|l|c|l|l|l|}
\hline No. & Colour & Name & Genotype & Cycling A.Green \\
\hline 1 & & Biantiao & & No Reaction \\
\hline 2 & & Changbo & & No Reaction \\
\hline 3 & & Ermaya & & No Reaction \\
\hline 4 & & Damaya & Wild Type & Reaction \\
\hline 5 & & Huangguo & & No Reaction \\
\hline 6 & & Panax notoginseng & & No Reaction \\
\hline 7 & & $\mathrm{H}_{2} \mathrm{O}$ & & No Reaction \\
\hline
\end{tabular}

Figure 3. Real-time allele-specific PCR amplification profile (upper) and allelic discrimination analysis of different Chinese ginseng samples (lower).

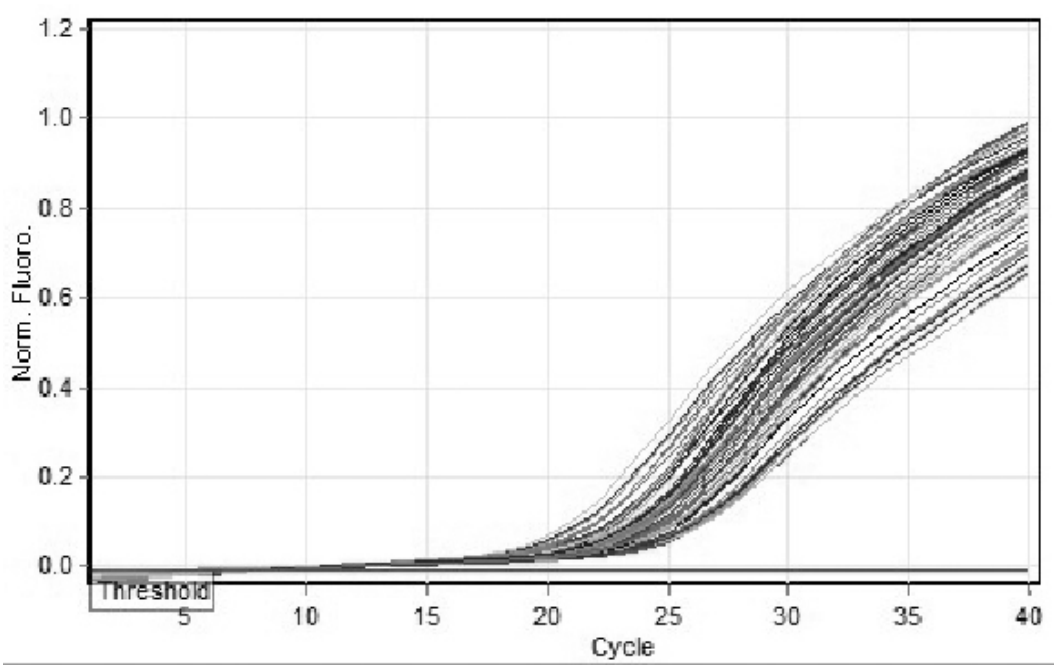

Figure 4. Accuracy of the authentication of 70 Damaya samples using real-time allele-specific PCR. 
related ginseng cultivars are distributed in the local population. In order to develop DNA markers for authenticating ginseng cultivars, some commonly used DNA barcodes have been analyzed, namely, internal transcribed spacer (ITS), external transcribed spacer (ETS), 5S spacer regions, and chloroplast intergenic spacer regions, but no intra-specific polymorphism was detected among the closely related cultivars. The mitochondrial cytochrome $\mathrm{c}$ oxidase subunit II locus has undergone multiple changes in its intron content during the evolution of dicotyledonous plants (Kudla et al., 2002). Thus, the mitochondrial cox 2 intron II region was used in the present study and was proved effective and reliable for the discrimination of Damaya. It could be concluded that the introns present in mitochondrial genome as well as EST-derived introns serve as potential pools for marker development of closely related crop cultivars.

Recently, different types of molecular markers have been developed to authenticate $P$. ginseng cultivars, namely, RAPD (random amplified polymorphic DNA) (Shao et al., 2004; Reunova et al., 2010), ISSR (inter simple sequence repeat) (In et al., 2005; Xu et al., 2010; Li et al., 2011), PCR-RFLP (restriction fragment length polymorphism) (Kim et al., 2007), AFLP (amplified fragment length polymorphism) (Ma et al., 2000; Reunova et al., 2010), and SSR (simple sequence repeat) (Choi et al., 2011; Kim et al., 2012; Li et al., 2013). However, these methods are not suitable for the selection of cultivars from large number of samples, as the fragment profiles of RAPD and ISSR are easily affected by minor change in PCR conditions. Additionally, RFLP and AFLP techniques use restriction enzyme digestion and tedious protocols. Although abundant SSR polymorphisms exist in the coding and non-coding sequences of $P$. ginseng, the size differences among PCR products of ginseng cultivars are so small that usually silver staining is needed after poly acrylamide gel electrophoresis (Hayashi et al., 2004).

Nowadays, a large amount of sequences are obtained by genomic and transcriptomic sequencing (Sathiyamoorthy et al., 2010; Li et al., 2013; Jayakodi et al., 2014), but development of cultivar-specific marker is still difficult as these sequences are usually generated from a single specific cultivar. Thus, it is not feasible to exploit SNPs by multiple alignments of redundant EST sequences. Alternatively, exploiting the SNPs present in the introns of coding regions is promising for rapid marker development. In this study, we discovered a Damaya cultivar-specific SNP marker present in the cox 2 intron II region. By combining a simple DNA isolation method with real-time PCR, the established method in this study removes the need for post-PCR manipulation, is simple, effective, timesaving, and is more suitable for highthroughput screening of ginseng cultivars. In summary, the present study provides a simple and rapid assay for the selection and conservation of Damaya from local Chinese ginseng populations. The proposed methodology could also be considered for the authentication of other closely related crop cultivars.

\section{ACKNOWLEDGMENTS}

Research supported by the National Natural Science Foundation of China (\#81503178).

\section{REFERENCES}

Choi HI, Kim NH, Kim JH, Choi BS, et al. (2011). Development of reproducible EST-derived SSR markers and assessment of genetic diversity in Panax ginseng cultivars and related species. J. Ginseng Res. 35: 399-412. http:// dx.doi.org/10.5142/jgr.2011.35.4.399

Choi J, Kim TH, Choi TY and Lee MS (2013). Ginseng for health care: a systematic review of randomized controlled trials 
in Korean literature. PLoS One 8: e59978. http://dx.doi.org/10.1371/journal.pone.0059978

Choi KT (2008). Botanical characteristics, pharmacological effects and medicinal components of Korean Panax ginseng C A Meyer. Acta Pharmacol. Sin. 29: 1109-1118. http://dx.doi.org/10.1111/j.1745-7254.2008.00869.x

D'Andrea M, Coïsson JD, Travaglia F, Garino C, et al. (2009). Development and validation of a SYBR-Green I real-time PCR protocol to detect hazelnut (Corylus avellana L.) in foods through calibration via plasmid reference standard. $J$. Agric. Food Chem. 57: 11201-11208. http://dx.doi.org/10.1021/jf902986t

Hayashi K, Hashimoto N, Daigen M and Ashikawa I (2004). Development of PCR-based SNP markers for rice blast resistance genes at the Piz locus. Theor. Appl. Genet. 108: 1212-1220. http://dx.doi.org/10.1007/s00122-003-1553-0

In DS, Chung J, Kim Y, Bang K, et al. (2005). Genetic relationships of Panax species by RAPD and ISSR analyses. Hanguk Yakyong Changmul Hakhoe Chi 13: 249-253.

Jayakodi M, Lee SC, Park HS, Jang W, et al. (2014). Transcriptome profiling and comparative analysis of Panax ginseng adventitious roots. J. Ginseng Res. 38: 278-288. http://dx.doi.org/10.1016/j.jgr.2014.05.008

Jee H-S, Chang K-H, Park S-H, Kim K-T, et al. (2014). Morphological characterization, chemical components, and biofunctional activities of Panax ginseng, Panax quinquefolium, and Panax notoginseng roots: A Comparative Study. Food Rev. Int. 30: 91-111. http://dx.doi.org/10.1080/87559129.2014.883631

Kim NH, Choi HI, Ahn IO and Yang TJ (2012). EST-SSR marker sets for practical authentication of all nine registered ginseng cultivars in Korea. J. Ginseng Res. 36: 298-307. http://dx.doi.org/10.5142/jgr.2012.36.3.298

Kim OT, Bang KH, In DS, Lee JW, et al. (2007). Molecular authentication of ginseng cultivars by comparison of internal transcribed spacer and 5.8 S rDNA sequences. Plant Biotechnol. Rep. 1: 163-167. http://dx.doi.org/10.1007/s11816$\underline{007-0019-2}$

Kudla J, Albertazzi FJ, Blazević D, Hermann M, et al. (2002). Loss of the mitochondrial cox 2 intron 1 in a family of monocotyledonous plants and utilization of mitochondrial intron sequences for the construction of a nuclear intron. Mol. Genet. Genomics 267: 223-230. http://dx.doi.org/10.1007/s00438-002-0657-6

Kwok S, Chang SY, Sninsky JJ and Wang A (1994). A guide to the design and use of mismatched and degenerate primers. PCR Methods Appl. 3: S39-S47. http://dx.doi.org/10.1101/gr.3.4.S39

Larkin MA, Blackshields G, Brown NP, Chenna R, et al. (2007). Clustal W and Clustal X version 2.0. Bioinformatics 23: 2947-2948. http://dx.doi.org/10.1093/bioinformatics/btm404

Li C, Zhu Y, Guo X, Sun C, et al. (2013). Transcriptome analysis reveals ginsenosides biosynthetic genes, microRNAs and simple sequence repeats in Panax ginseng C.A. Meyer. BMC Genomics 14: 245. http://dx.doi.org/10.1186/14712164-14-245

Li S, Li J, Yang X-L, Cheng Z, et al. (2011). Genetic diversity and differentiation of cultivated ginseng (Panax ginseng C A Meyer) populations in North-east China revealed by inter-simple sequence repeat (ISSR) markers. Genet. Resour. Crop Evol. 58: 815-824. http://dx.doi.org/10.1007/s10722-010-9618-9

Ma XJ, Wang XQ, Xiao PG and Hong DY (2000). [A study on AFLP fingerprinting of land races of Panax ginseng L]. Zhongguo Zhong Yao Za Zhi 25: 707-710.

Reunova GD, Kats IL, Muzarok TI and Zhuravlev Yu N (2010). Polymorphism of RAPD, ISSR and AFLP markers of the Panax ginseng C.A. Meyer (Araliaceae) genome. Genetika 46: 1057-1066.

Sathiyamoorthy S, In JG, Gayathri S, Kim YJ, et al. (2010). Generation and gene ontology based analysis of expressed sequence tags (EST) from a Panax ginseng C.A. Meyer roots. Mol. Biol. Rep. 37: 3465-3472. http://dx.doi. org/10.1007/s11033-009-9938-z

Shao AJ, Li X, Huang LQ, Wei JH, et al. (2004). [Genetic analysis of cultivated ginseng population with the assistance of RAPD technology]. Zhongguo Zhong Yao Za Zhi 29: 1033-1036.

Sun H, Wang HT, Kwon WS, In JG, et al. (2010). Development of molecular markers for the determination of the new cultivar 'Chunpoong' in Panax ginseng C. A. Meyer associated with a major latex-like protein gene. Biol. Pharm. Bull. 33: 183-187. http://dx.doi.org/10.1248/bpb.33.183

Sun H, Wang HT, Kwon WS, Kim YJ, et al. (2011). A simple and rapid technique for the authentication of the ginseng cultivar, Yunpoong, using an SNP marker in a large sample of ginseng leaves. Gene 487: 75-79. http://dx.doi. org/10.1016/j.gene.2011.05.021

Wang H, Qi M and Cutler AJ (1993). A simple method of preparing plant samples for PCR. Nucleic Acids Res. 21: 4153 4154. http://dx.doi.org/10.1093/nar/21.17.4153

Wang H, Sun H, Kwon WS, Jin H, et al. (2009). Molecular identification of the Korean ginseng cultivar "Chunpoong" using the mitochondrial nad7 intron 4 region. Mitochondrial DNA 20: 41-45. http://dx.doi.org/10.1080/19401730902856738

Wang H, Sun H, Kwon WS, Jin H, et al. (2010). A simplified method for identifying the Panax ginseng cultivar Gumpoong based on 26S rDNA. Planta Med. 76: 399-401. http://dx.doi.org/10.1055/s-0029-1186161

Wang H, Kwon WS, Yang DU, Kim MK, et al. (2011). Development of a multiplex amplification refractory mutation 
system for simultaneous authentication of Korean ginseng cultivars "Gumpoong" and "Chungsun". Mitochondrial DNA 22: 35-38. http://dx.doi.org/10.3109/19401736.2011.588216

Xu Y-h, Zhang A-h, Jin H, Bang K-H, et al. (2010). Genetic relationship analysis of ginseng by ISSR analysis. Chin. Tradit. Herbal Drugs 41: 1164-1167.

Zhang G, Liu A, Zhou Y, San X, et al. (2008). Panax ginseng ginsenoside-Rg2 protects memory impairment via antiapoptosis in a rat model with vascular dementia. J. Ethnopharmacol. 115: 441-448. http://dx.doi.org/10.1016/j. jep.2007.10.026

Zhao Y-h, Gu X-h, Wu L-j and You W (2007). Researches on categories, characteristics, and utilization value of cultivated ginseng germplasm resources. Chin. Tradit. Herbal Drugs 38: 294-296. 